\title{
Effect of ardhabilva kvatha curna- an ayurvedic formulation on lipid profile after chronic administration
}

\author{
Md. Sohel Kabir ${ }^{1}$, Kaiser Hamid ${ }^{2 \star}$, Latifa Bulbul ${ }^{3}$, Zubaida Khatun ${ }^{4}$, Md. Zahid Alam \\ Paritosh Chakma ${ }^{1}$ \\ ${ }^{1}$ Department of Pharmacy, Jahangirnagar University, Savar, Dhaka, Bangladesh \\ ${ }^{2}$ Department of Pharmacy, Southeast University, Banani, Dhaka, Bangladesh \\ Cell: +8801926759309, Email: kaiserpharm_1134@yahoo.com \\ ${ }^{3}$ Department of Pharmacy, Gono Bishwabidyalay, Savar, Dhaka, Bangladesh \\ ${ }^{4}$ Department of Pharmacy, University of Development Alternative, Dhanmondi, Dhaka , \\ Bangladesh \\ * Corresponding author: Kaiser Hamid, Lecturer, Department of Pharmacy, Southeast \\ University Banani, Dhaka, Bangladesh , Cell: +8801926759309, Email: \\ kaiserpharm_1134@yahoo.com
}

\begin{abstract}
Ardhabilva Kvatha Curna (ADR) is a poly herbal Ayurvedic preparation that is traditionally used in Bangladesh for the treatment Malabandha (obstructed feces). The present study was undertaken to observe the effect of this formulation on lipid profile reveals that it possesses hypotriglyceridemic property. The change in the lipid profile both in the male and female rats was in the same trend except Very Low Density Lipoprotein. In the male rats there was a statistically significant decrease in the Triglycerides $\left(p=0.001^{\star \star \star}\right)$. Similar trend was observed in case of total cholesterol $(p=0.491)$, Very Low Density Lipoprotein $(p=0.673)$ and Low Density Lipoprotein $(p=$ 0.211 ) but these decrease was not statistically significant. There was statistically insignificant increase was observed incase of High Density Lipoprotein $(p=0.784)$. In the female rats there was a statistically significant decrease in the Triglycerides $\left(p=0.001^{\star \star *}\right)$. In case of total cholesterol $(p=0.381)$ High Density Lipoprotein $(p=0.714)$, Low Density Lipoprotein $(p=0.131)$, there was not remarkable change in comparison with control groups. In the female rats the amount of Very Low Density Lipoprotein was increased that was different from male rats.
\end{abstract}

Keywords: Ardhabilva Kvatha Curna (ADR), lipid profile, Ayurvedic formulation

\section{INTRODUCTION}

Ayurvedic medicine, also called Ayurveda, originated in India several thousand years ago and in the United States, Ayurvedic medicine is considered a type of CAM and a whole medical system. Ayurvedic medicine continues to be practiced in India, where nearly 80 percent of the population uses it exclusively or combined with conventional (Western) medicine. It is also practiced in Bangladesh, Sri Lanka, Nepal, and Pakistan.

Ardhabilva Kvatha Curna is an Ayurvedic formulation which is included in the Bangladesh National Formulary of Ayurvedic Medicine 1992 (Approved by the Government of Bangladesh vide Ministry of Health and Family Welfare Memo No. Health1/Unani-2/89/ (Part-1) 116 dated 3-6-1991). It is indicated in the treatment of Malabandha (obstructed feces).
Actually, it is a preparation in which five important medicinal plants are used in particular amount (Table 1). It includes Zingiber officinale (Ginger) belonging to the family Zingiberaceae is widely used all around the world as a spice or food additive and medicine. Isolation of different chemical compounds having important medicinal value has been reported from the rhizome of this plant which includes oleoresingingeroles, shogaols and zingerone those are credited for use as anti-nausea or antiemetic, abortifacient, antimicrobial, anti-inflammatory (Verma SK et al., 1994) antioxidant (Shobana S et al., 2000) anticoagulant, antihypercholesterolemic, antihypertensive, antihyperglycaemic, antispasmodic, aperient (Bradley PR, 1992) alexeteric, circulatory stimulant, counter irritant, sialagogue and vasodilator effects. 
Table 1: Formulary of ADR

\begin{tabular}{|l|l|l|l|l|}
\hline \multicolumn{1}{|c|}{ Name of Plants I Ingredients } & Used Parts & \multicolumn{1}{c|}{ Botanical Name } & \multicolumn{1}{c|}{$\begin{array}{c}\text { Family } \\
\text { Used }\end{array}$} \\
\hline Cukku (sunthi) & Rhizome & Zingiber officinale & Zingiberaceae & $24 \mathrm{~g}$ \\
\hline Katalati mula (apamarga) & Root & Achyranthes aspera linn & Amaranthaceae & $24 \mathrm{~g}$ \\
\hline Cunda mula (brhatibheda) & Root & Solanum Xanthocarpum & Solanaceae & $24 \mathrm{~g}$ \\
\hline Tuva mula (duralabha) & Root & Fagonia cretica Linn & Zygophyllaceae & $24 \mathrm{~g}$ \\
\hline Tazutama mula (punarnava) & Root & Boerhaavia diffusa & Nyctaginaceae & $24 \mathrm{~g}$ \\
\hline
\end{tabular}

Solanum xanthocarpum belonging to the family Solanaceae, commonly known as the Indian night shade or Yellow berried night shade, is a prickly, diffusely bright-green, perennial shrub which grows abundantly in arid areas of India. Traditionally different parts of this plant have been used for curing various ailments. Fruit juice is useful in sore throats and rheumatism; decoction of the plant is used in gonorrhea; paste of leaves is applied to relieve pains; seeds act as expectorant in cough and asthma; roots are expectorant and diuretic, useful in the treatment of catarrhal fever, coughs, asthma and chest pain (Ghani, 1998).

Achyranthes aspera Linn belonging to the family Amaranthaceae, a genus of herbs or small shrubs, is distributed throughout the tropical and subtropical regions. Isolation various chemical compounds including contains saponins, betaine, achyranthine, amino acids, $B$-ecdysone, hentriacontane, lauric acid, myristic acid, ß-sitosterol, stigmasterol, oleanolic acid and its glucoside, indole aceticacid oxidase and flavonoids have been reported by Raman and Faroque, 1996 and Seshatri et al., 1981. The use of this plant as an emmenagogue, antiarthritic, purgative, diuretic, antimalarial, antihyperlipidaemic, oestrogenic, antileprotic, antispasmodic, cardiotonic, antibacterial and antiviral agent have been reported by Desta, 1993; Gessler et al., 1994; Khanna et al., 1992

Boerhaavia diffusa also termed as Punarnava belonging to the Family Nyctaginaceae is a creeping weed found abundantly all over India. In Indian traditional medicine, the roots of $B$. diffusa are used for the treatment of dyspepsia, jaundice, enlargement of spleen, abdominal pain and as an antistress agent in the Indian traditional Medicine [Kirtikar KR, Chopra $\mathrm{RN}, 1996]$. Liriodendrin isolated from the methanolic extract of its root has a significant calcium channel antagonistic activity and the decoction of its leaves is used in Martinican folk medicine for analgesic and anti-inflammatory properties [Lami N et al., 1991, Hiruma-Lima CA et al., 2000]. The aqueous extract of $B$. diffusa roots induces leukocytosis with predominant neutrophilia, associated with a stimulation of the phagocytic and bactericidal capacity of neutrophils and macrophages and protects mice against Escherichia coli-induced peritonitis [Mungantiwar AA et al., 1997].

Fagonia cretica $L$ belonging to the family Zygophyllaceae is a small spiny undershrub. (Chopra RM et al., 2000, Hooker JD et al., pp 1881). It is reputed to be a medicinal plant in scientific and folkloric literature, and its medicinal values are well documented (Saeed MA, 1969). F. cretica is astringent, febrifuge and prophylactic against smallpox. The plant is bitter and used for the treatment of fever, thirst, vomiting, dysentery, asthma, urinary discharges, liver trouble, typhoid, toothache, stomach troubles and skin diseases (Baquar SR, 1989). Boiled residue of the plant in water is used to induce abortion. It is externally applied as a paste on tumors and other swellings of the neck. An aqueous decoction of the plant is a popular remedy for cancer in the indigenous system of medicine (Saeed MA, 1969).

The present study was undertaken to explore the effect of this formulation on the lipid profile so that it could be presumed whether it can be used in the treatment of lipid disorders or not.

\section{MATERIALS AND METHODS}

Chemicals and Reagents: All the reagents and chemicals that were used in this work were of analytical grade and were prepared in all glassdistilled water. To evaluate the lipid profile of Ardhabilva Kvatha Curna (ADR), it was collected from Sree Kundshawri Aushadhalaya Ltd, Chittagong.

Dose and route of administration: The liquid Ardhabilva Kvatha Curna was administered to the animals at a volume such that it would permit optimal dosage accuracy without contributing much to the total increase in the body fluid. For investigating the lipid profile, the drugs were administered per oral route at a dose of $40 \mathrm{ml} / \mathrm{kg}$ body weight. For all the studies, the drug was administered orally. [per oral 
(p.o.) route]. Ketamine was administered intraperitoneally (500 mg/kg i.p.).

Experimental animals and their Management: Forty eight-week old albino rats (Rattus novergicus : Sprague-Dawley strain,) of both sexes, bred and maintained at the Animal House of the Department of Pharmacy, Jahangirnagar University were used in this experiment. These animals were apparently healthy and weighed $50-70 \mathrm{~g}$.

The animals were housed in a well ventilated hygienic experimental animal house under constant environmental and adequate nutritional conditions throughout the period of the experiment. All of the rats were kept in plastic cages having dimensions of $30 \times 20 \times 13 \mathrm{~cm}$ and soft wood shavings were employed as bedding in the cages. Feeding of animals was done ad libitum, along with drinking water and maintained at natural day night cycle.

They were fed with "mouse chow" (prepared according to the formula developed at BCSIR, Dhaka). All experiments on rats were carried out in absolute compliance with the ethical guide for care and use of laboratory animals.

Before starting the experiment the animals were carefully marked on different parts of their body, which was later used as identification mark for a particular animal, so that the response of a particular rat prior to and after the administration could be noted separately.

A group of equal number of rat as the drug treated group was simultaneously employed in the experiment. They were administered with distilled water as placebo as par the same volume as the drug treated group for the same number of days and this group served as the control. Prior to the experiment, they were randomly divided into 4 groups of 10 animals / sex. Thus ten rats were taken for each group for both control and the experimental group

Preparation of the Plasma for intended Test: At the due of the 41-day treatment period, the animals were fasted for 18 hours and also twenty-four hours after the last administration, the animals were anaesthetized using i.p. Ketamine (500 mg/kg i.p.). Blood samples were collected from post vena cava and transferred into heparinised tubes immediately. Blood was then centrifuged at 4,000 $\mathrm{g}$ for $10 \mathrm{~min}$ using bench top centrifuge (MSE Minor, England) to remove red blood cells and recover plasma. Plasma samples were separated and were collected using dry Pasteur pipette and stored in the refrigerator for analyses. All analyses were completed within $24 \mathrm{~h}$ of sample collection.

Determination of Lipid profile: Triglycerides, Total Cholesterol and HDL concentration were evaluated according to the instruction of manufacturer of assay kits (purchased from Sigma Chemical Co, St Louis, MO, USA). According to Friedewald's formula (Friedewald et al., 1972) VLDL and LDL were calculated as: VLDL cholesterol $=\mathrm{TG} / 5$ and $\mathrm{LDL}$ cholesterol $=\mathrm{TC}-(\mathrm{VLDL}+\mathrm{HDL}$ cholesterol $)$.

Statistical Analysis: The group data are expressed as Mean \pm SEM (Standard Error of the Mean). Unpaired " $t$ " tests were done for statistical significance tests. SPSS (Statistical Package for Social Science) for WINDOWS (Ver. 11) was applied for the analysis of data. Differences between groups were considered significant at $p<0.05,0.01$ and 0.001 .

\section{RESULTS AND DISCUSSION}

In the male rats there was a statistically significant decrease in the Triglycerides $\left(p=0.001^{\star \star \star}\right)$. On the other hand except HDL there was not notable decrease in total cholesterol $(p=0.491)$, VLDL $(p=0.673)$ and LDL $(p=0.211)$. There was statistically insignificant increase was observed incase of $\mathrm{HDL}$ $(p=0.784)$. The similar result was observed incase of female rats except VLDL. In the female rats there was a statistically significant decrease in the Triglycerides $\left(p=0.001^{\star * \star}\right)$. In case of total cholesterol $(p=0.381) \mathrm{HDL}(p=0.714), \operatorname{LDL}(p=0.131)$, there was not remarkable change in comparison with control groups. In the female rats the amount of VLDL was increased that was different from male rats (Table 2, Graph 1 and 2). 
Agric. Biol. J. N. Am., 2010, 1(5): 812-816

Table 2: Effect of ADR on lipid profile

\begin{tabular}{|c|c|c|c|c|c|c|}
\hline \multirow[t]{2}{*}{ Parameters } & \multicolumn{3}{|l|}{ Male Rats } & \multicolumn{3}{|c|}{ Female Rats } \\
\hline & Control $(n=10)$ & $\operatorname{ADR}(n=10)$ & P values & Control $(n=10)$ & ADR $(n=10)$ & $\mathbf{P}$ values \\
\hline Triglycerides & $93.2089 \pm 1.6064$ & $51.0296 \pm 1.4122$ & $0.001^{* * *}$ & $103.9769 \pm 3.4572$ & $53.9559 \pm 2.0858$ & $0.001^{\star \star \star}$ \\
\hline Total cholesterol & $67.5683 \pm 1.5603$ & $66.6704 \pm 1.8255$ & $0.491^{\star \star \star}$ & $81.8736 \pm 1.7432$ & $79.6274 \pm 1.4725$ & $0.381^{\star \star \star}$ \\
\hline VLDL & $15.0378 \pm 0.6275$ & $14.3314 \pm 0.4792$ & $0.673^{\star \star \star}$ & $18.7173 \pm 0.5858$ & $19.4338 \pm 0.6128$ & $0.410^{\star \star \star}$ \\
\hline LDL & $18.9897 \pm 0.6952$ & $17.9785 \pm 0.5727$ & $0.211^{\star}$ & $20.2930 \pm 0.7952$ & $22.4038 \pm 0.7085$ & $0.131^{*}$ \\
\hline HDL & $30.8108 \pm 0.8295$ & $30.8935 \pm 0.7216$ & $0.784^{\star \star \star}$ & $35.1861 \pm 1.0213$ & $35.7335 \pm 0.9894$ & $0.714^{\star \star \star}$ \\
\hline
\end{tabular}

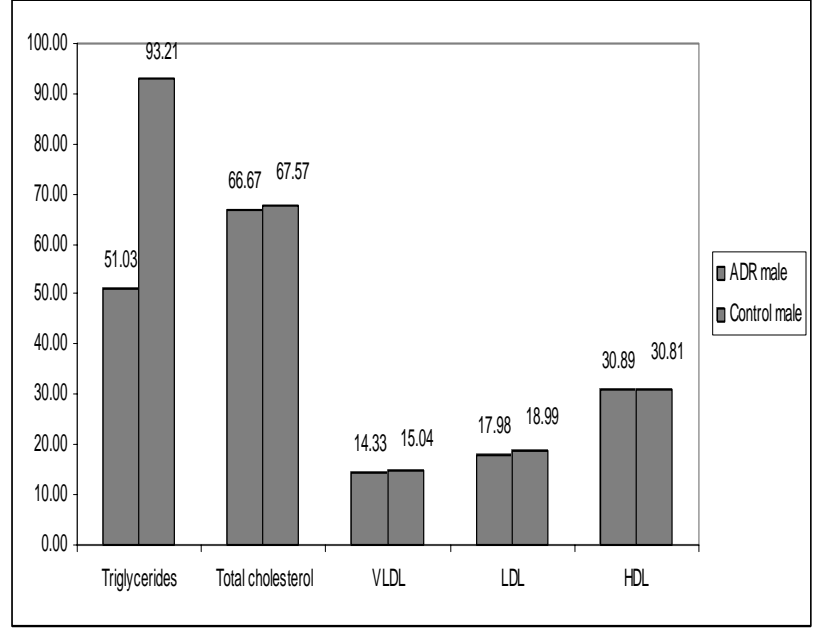

Graph 1: Comparative graphical representation of lipid profile between control and drug male rats.

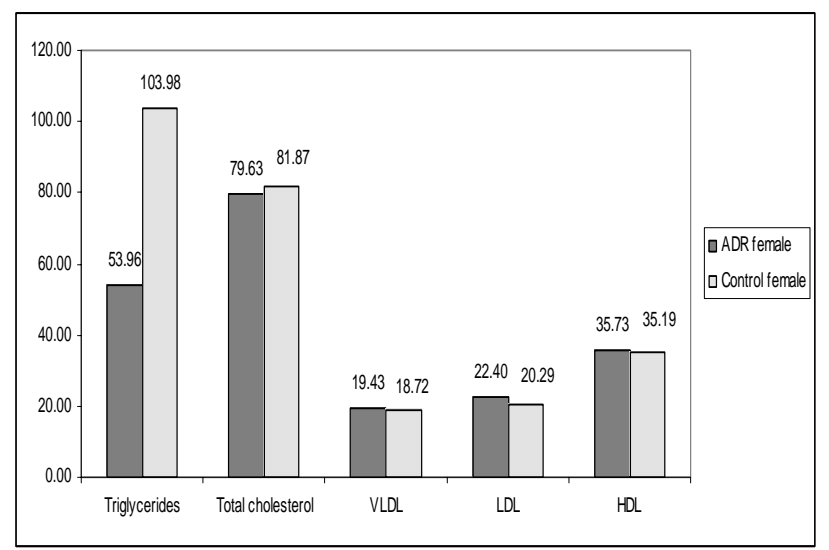

Graph 2: Comparative graphical representation of lipid profile between control and drug female rats.
The observed hypotriglyceridemic effect of this formulation both in male and female rats may be due to a decrease of fatty acids synthesis (Bopanna et al., 1997), enhanced catabolism of LDL, activation of LCAT and tissues lipases (Khanna et al., 2002) and/or inhibition of cetyl-CoA carboxylase (Mc Carty, 2001) and production of triglycerides precursors such acetyl-CoA and glycerol phosphate.

The increase the level of HDL by increasing the activity of LCAT, which may contribute to the regulation of blood lipids. LCAT play a key role in lipoprotein metabolism and most of the lipoprotein changes are the outcome of primary abnormality owing o the liver diseases (Seidel and Wall, 1983). It also incorporates free cholesterol into HDL and transferring back to VLDL or IDL, which is taken back by the liver cells (Rajlakshmi and Sharma, 2004).

The decrease in cholesterol in the both sexes of the animal may be due to the decrease in absorption from the intestine, by binding with bile acids within the intestine and increasing bile acids excretion (Kritchevsky, 1978; Kelly and Tsai, 1978).

\section{CONCLUSION}

The Ayurvedic formulation Ardhabilva Kvatha Curna (ADR) may be useful in the treatment of hypertriglycerdemia. The effect of this formulation on VLDL is different in male and female rats. It necessitates precise study of this preparation on this parameter to find out the reason of this sex dependency.

\section{ACKNOWLEDGEMENT}

The authors are grateful to Professor M. S. K. Choudhuri, Department of Pharmacy, Jahangirnagar University for his kind supervision during the research work and thankful to Mr. Shafiqur Rahman for his technical assistance. 


\section{REFERENCES}

Baquar SR (1989). Medicinal and Poisonous Plants of Pakistan. Printas. Karachi: pp. 198-199.

Bopanna, K.N., Kannan, J., Gadgil, S., Balaraman, E.R., Rathore, S.P (1997). Antidiabetic and antihyperglycaemic effects of neem seed kernel powder on alloxan diabetic rabbits. Indian Journal of Pharmacology 9, 162-167.

Bradley PR (1992). British Herbal Compendium, Vol 1. British Herbal Medicine Association, Bournemouth, Dorset, UK 112-114.

Chopra RN, Nayar SL, Chopra IC (1996). Glossary of Indian medicinal plants. New Delhi, National Institutes of Science Communication.

Chopra RM, Handa KL, Kapur LD (1982). Indigenous Drugs of India (2nd ed). Academic Publisher. New Delhi.

Desta B (1993). Ethiopian traditional herbal drugs part II: Antimicrobial activity of 63 medicinal plants. $J$ Ethnopharmacol 39: 129-139

Friedewald WT, Levy RI and Fredrickson DS (1972). Estimation of the concentration of Low-Density Lipoprotein Cholesterol in plasma, without use of the preparative ultracentrifuge, Clinical Chemistry, 18(6): 499-502.

Ghani A (1998). Medicinal plants of Bangladesh - chemical constituents and uses. Dhaka: Asiatic Society of Bangladesh.

Gessler MC, Nkunyak MHH, Tanner M (1994). Screening medicinal plants for antimalarial activity. Acta Trop 56: 65-77

Hiruma-Lima CA, Gracioso JS, Bighetti EJ, Germonsen Robineou L, Souza Brito AR (2000). The juice of fresh leaves of Boerhaavia diffusa L. (Nyctaginaceae) markedly reduces pain in mice. J Ethnopharmacol; 71:267-74.

Hooker JD (1881). Thomson T. The Flora of British India. William Clowes and Sons Ltd. London.

Khanna AK, Chandra A, Singh C, Srivastava AK, Kapoor N (1992). Hypolipidemic activity of Achyranthes aspera in normal and triton induced hyperlipidemic rats. J Exp Biol 30: 128-130
Kirtikar KR, Basu BD. Lalit Mohan Basu, Allahabad, India. 2nd edn. Indian Medicinal Plants, vol. 3. p. 2045-8.

Khanna, K., Rizvi, F., Chander, R (2002). Lipid lowering activity of Phyllanthus iruri in hyperlipemic rats. Journal of Ethnopharmacology 82, 9-22.

Kritchevsky, D (1978): Fiber, lipids and atherosclerosis. American Journal of Clinical Nutrition 31S, 65-74.

Kelly J.J, Tsai, A.C (1978). Effect of pectin, gum Arabic and agar on cholesterol absorption, synthesis and turnover in rats. Journal of Nutrition 108, 630-639.

Lami N, Kadota S, Kikuchi T, Momose Y (1991): Constituents of the roots of Boerhaavia diffusa $L$. Identification of $\mathrm{Ca} 2+$ channel antagonistic compound from the methanol extract. Chem Pharm Bull (Tokyo) 39:1551- 5 .

Mungantiwar AA, Nair AM, Saraf MN (1997). Adaptogenic activity of aqueous extract of the roots of Boerhavia diffusa Linn. Indian Drugs; 34:184.

Mc Carty, M.F., (2001). Inhibition of acetyl-CoA carboxylase by cystamine may mediate the hypotriglyceridemic activity of pantetheine. Medical hypotheses 56, 314-317.

Rahamn MH, Farooque ASM (1996). Studies on the antibacterial properties of Achyranthes aspera stem. Fitoterapia LXII: 92-93

Rajlakshmi D., Sharma, D.K (2004). Hypolipidemic effect of different extracts of Clerodendron colebrookranum in normal and high-fat diet fed rats. Journal of Ethnopharmacology, 90, 63-68.

Shobana S, Naidu KA (2000). Antioxidant activity of selected Indian spices. Prostaglandins Leukot Essent Fatty Acids. 62: 107-110.

Seshatri V, Batta AK, Rangaswami S (1981). Structure of two saponins from Achyranthes aspera. Indian J Chem Ser 20: 773-775

Saeed MA (1969). Hamdard Pharmacopoeia of eastern medicine. Hamdard Pharmacopoeia. 1.

Seidel, D., Wall, A (1983). In: Landman, L., Staddler, G.A. (Eds.), liver in Metabolic Diseases. MIP Press, Lancaster, England, pp.81-95.

Verma SK, Singh J, Khamesra R (1994). Effect of ginger on platelet aggregation in man. Indian $\mathrm{J}$ Med Res 98: 240-242. 